\title{
Free prostate-specific antigen outperforms total prostate-specific antigen as a predictor of prostate volume in patients without prostate cancer
}

\author{
Sinan Avci, Efe Onen, Volkan Caglayan, Metin Kilic, Murat Sambel, Sedat Oner \\ University of Health Sciences, Bursa Yuksek Ihtisas Training and Research Hospital, Department of Urology, Bursa, Turkey.
}

\begin{abstract}
Summary Objective: In the management of benign prostatic hyperplasia $(\mathrm{BPH})$, urology guidelines recommend medical or surgical treatments according to different prostate volumes $(\mathrm{PV})$. The aim of this study was to analyze the relationships between $P V$ and age, total and free prostate specific antigen (tPSA, fPSA) and fPSA/tPSA ratio in patients without histologically proven prostate cancer.

Materials and methods: A retrospective analysis was made of the data of 1334 patients who underwent transrectal ultrasound (TRUS)-guided prostate biopsy between January 2016 and October 2018. A total of 438 patients with available data for age, tPSA and fPSA levels and PV calculated by TRUS were enrolled in the study. Patients with chronic prostatitis pathology in addition to BPH were also noted and evaluated as a separate group.

Results: There were significant correlations between PV and age, tPSA, fPSA, fPSA/tPSA ratio $(r=0.210, r=0.338$, $r=0.548, r=0.363$ respectively). In multivariate linear regression analysis, PPSA was found to be the only predictor for PV $(p<0.001)$ when compared to age $(p=0.097)$, tPSA $(p=0.979)$ and fPSA/tPSA ratio $(p=0.425)$. In patients with chronic prostatitis pathology there were significant correlations between PV and age, tPSA, fPSA, fPSA/tPSA ratio $(r=0.279, r=0.379, r=0.592, r=0.359$, respectively). The multivariate linear regression analysis showed a significant correlation only between PV and TPSA and fPSA/tPSA ratio but not with $\mathrm{PPSA}$ and age $(p=0.008, p=0.015$, $p=0.430, p=0.484$, respectively). In men with only BPH pathology there were significant correlations between $P V$ and age, tPSA, fPSA, fPSA/tPSA ratio $(r=0.223, r=0.385$, $r=0.520, r=0.287$, respectively) In multivariate linear regression model the significant correlation was shown only between PV and PPSA $(p<0.001)$.

Conclusions: Although tPSA was significantly correlated with $P V$ in patients without prostate cancer, the correlation between fPSA and PV was much stronger. However, it should be kept in mind that the efficacy of fPSA may be limited in patients with clinically unknown prostatic inflammation.
\end{abstract}

KEY WORDS: Benign prostatic hyperplasia; Chronic prostatitis; Free prostate-specific antigen; Free prostate-specific antigen/total prostate-spesific antigen ratio; Prediction; Prostate-specific antigen; Prostate volume.

Submitted 18 July 2019; Accepted 1 September 2019

\section{INTRODUCTION}

Lower urinary tract symptoms (LUTS) have traditionally been related to bladder outlet obstruction, which is often caused by benign prostatic enlargement resulting from the histological condition of benign prostatic hyperplasia (BPH) $(1,2)$. Prostate volume (PV) predicts symptom progression and the risk of complications such as urinary retention (3). PV may also be determinative in the decision for BPH treatment. For example, in urology guidelines the use of 5 alpha reductase inhibitors in prostate volumes $>40 \mathrm{cc}$ is recommended for medical treatment. Surgical treatment options also vary according to the prostate volume in guidelines (4). Therefore, it is important to know the PV correctly for the prognosis and treatment of the disease.

Digital-rectal examination (DRE) is the simplest way to assess PV, but the correlation to $\mathrm{PV}$ is poor.

Underestimation of PV by DRE increases with increasing transrectal ultrasound (TRUS) volume, particularly where the volume is $>30 \mathrm{~mL}$ (5). TRUS is more accurate in determining PV than DRE and transabdominal ultrasound so it is the standard method recommended for measurement of PV $(6,7)$ However, it is an expensive, time-consuming, and uncomfortable modality for the initial evaluation of men with LUTS. Therefore, another cheaper and simply applicable method, other than DRE is needed to predict the PV correctly in our daily practice. The prediction of PV can be based on total and free prostate specific antigen (PSA). Both PSA forms predict the TRUS prostate volume $( \pm 20 \%)$ in $>90 \%$ of cases $(8,9)$. The aim of this study was to analyze the relationships between total PSA, free PSA, age and prostate volume in patients with histologically proven $\mathrm{BPH}$.

Furthermore, the implication of the use of free PSA as a proxy marker to estimate PV was analyzed.

\section{MATERIALS AND METHOdS}

The data of 1334 men who underwent transrectal ultrasound (TRUS) guided prostate biopsy between January 2016 and October 2018 were analyzed retrospectively. Approval for the study was granted by the Local Ethics Committee (reg. no: 2011-KAEK-25 2018/11-03).

Patients with pathological results of cancer, prostatic intraepithelial neoplasia (PIN) or atypical small acinar proliferation (ASAP), aged < 40 years, with PSA levels $>30 \mathrm{ng} / \mathrm{dl}$, with a history of 5alpha-reductase inhibitor therapy, phytotherapy or any invasive therapy for BPH were excluded. Patients who had a cystoscopy, colonoscopy, TRUS, prostate biopsy, acute prostatitis, 
urinary tract infection and urinary retention during the previous month were also omitted. Those with a subsequent positive prostate biopsy were also excluded, and those with negative prostate biopsies were included. The pathology reports with chronic prostatitis in addition to $\mathrm{BPH}$ were also noted.

The PV of the patients were calculated by measuring three dimensions of the prostate with TRUS, and using the ellipsoid formula (PV=height*width*length*0.52). For prostate enlargement, a volume of $40 \mathrm{ml}$ was considered as the cut-off value. Serum PSA levels were measured using the chemiluminescent microparticle immunoassay (CMIA) method prior to any prostate manipulation, including DRE, TRUS and biopsy.

A total of 438 patients who met the inclusion criteria, with the available data of age, total-free PSA levels and PV calculated by TRUS were enrolled in the study. Patients were stratified by age into three groups: $<60$ years, 60-70 years and $>70$ years. Patients with PSA levels < 10ng/dl and PSA levels between $10 \mathrm{ng} / \mathrm{dl}$ and 30ng/dl were also evaluated as two separate groups.

Data obtained in the study were analysed using SPSS version 15.0 software (SPSS, Inc., Chicago, IL, USA). Correlation and linear regression analyses were performed to evaluate the relationships between age, total PSA, free PSA and PV. Receiver operating characteristics (ROC) curves were constructed to evaluate the ability of free PSA to predict PV for the entire cohort and each subgroup. A value of $\mathrm{p}<0.05$ was accepted as statistically significant.

\section{REsULTS}

A total of 896 patients with any exclusion criteria or with incomplete data were excluded from the study.

The remaining 438 patients had a mean age of $64.82 \pm$ 7.18 years, median total PSA value of $6.82 \mathrm{ng} / \mathrm{dl}$ (min- $\max =2.75-29.85)$, median free PSA value of 1.68 (min$\max =0.24-11.25)$, median free PSA/total PSA ratio of 0.235 (min- $\max =0.02-0.82$ ) and median PV of $74 \mathrm{cc}$ (min-max $=40-422)$. The baseline characteristics of the entire cohort and each subgroup are shown in Table 1. Statistically significant correlations were determined between PV and age, total PSA, free PSA, free PSA/total PSA ratio when the entire cohort was analyzed $(p<0.001$ and $r=0.210, p<0.001$ and $r=0.338, p<0.001$ and $r$ $=0.548, p<0.001$ and $r=0.363$ respectively) (Table 2 ). Free-PSA was found to be the only predictor for PV $(\mathrm{p}<$ $0.001)$ in the multivariate linear regression model when compared to age $(p=0.097)$, total PSA $(p=0.979)$ and free PSA/total PSA ratio ( $p=0.425)$ (Table 3$)$.

Patients with chronic prostatitis pathology and patients with pathology reported as BPH only were evaluated separately. In the chronic prostatitis group there were significant correlations between PV and age $(\mathrm{p}=0.011$ and $\mathrm{r}=$ $0.279)$, total PSA $(p<0.001$ and $r=0.379)$, and free PSA $(p<0.001$ and $r=0.592)$, fPSA/tPSA ratio $(p<0.001$ and $r=0.359$ ) (Table 2 ). In the multivariate linear regression model, a significant correlation was shown only between PV and tPSA, fPSA/tPSA ( $p=0.008, p=0.015$ respectively) (Table 3 ). In the $\mathrm{BPH}$ only group, there were significant correlations between PV and age ( $\mathrm{p}<$ 0.001 and $r=0.223)$, total PSA $(p<0.001$ and $r=$ $0.385)$, free PSA $(\mathrm{p}<0.001$ and $\mathrm{r}=0.520)$ and fPSA/tPSA ratio ( $p<0.001$ and $r=0.287$ ) (Table 2 ).

In the multivariate linear regression model, a significant correlation was shown only between PV and PPSA ( $\mathrm{p}<$ 0.001) (Table 3)

There were correlations between free PSA and PV in all three age groups $(<60$ years $p<0.001$ and $r=0.546,60$ 70 years $\mathrm{p}<0.001$ and $\mathrm{r}=0.506,>70$ years $\mathrm{p}<0.001$ and $r=0.483$ ) (Table 4). There were correlations between free PSA and PV when the cohort was separated according to total PSA value as below or above $10 \mathrm{ng} / \mathrm{dl}$

Table 1.

Characteristics of the patient population.

\begin{tabular}{|c|c|c|c|c|c|c|c|}
\hline & & $\begin{array}{l}\text { Number } \\
\text { of patients }\end{array}$ & $\begin{array}{l}\text { Age (years) } \\
\text { (mean } \pm \text { SD) }\end{array}$ & $\begin{array}{l}\text { Total PSA (ng/dl) } \\
\text { (median, min-max) }\end{array}$ & $\begin{array}{l}\text { Free PSA (ng/dl) } \\
\text { (median, min-max) }\end{array}$ & $\begin{array}{c}\text { fPSA/tPSA ratio } \\
\text { (median, min-max) }\end{array}$ & $\begin{array}{l}\text { Prostate volume (cc) } \\
\text { (median, min-max) }\end{array}$ \\
\hline \multirow[t]{3}{*}{ Age groups } & $<60$ & $\begin{array}{c}121 \\
(28 \%)\end{array}$ & $56.05 \pm 3.66$ & $\begin{array}{c}5.59 \\
(2.75-29.85) \\
\end{array}$ & $\begin{array}{c}1.20 \\
(0.24-7.74)\end{array}$ & $\begin{array}{c}0.208 \\
(0.03-0.69)\end{array}$ & $\begin{array}{c}61 \\
(40-290)\end{array}$ \\
\hline & $60-70$ & $\begin{array}{c}224 \\
(51 \%)\end{array}$ & $65.43 \pm 2.72$ & $\begin{array}{c}7.19 \\
(2.9-28.62)\end{array}$ & $\begin{array}{c}1.70 \\
(0.36-9.56)\end{array}$ & $\begin{array}{c}0.24 \\
(0.02-0.82)\end{array}$ & $\begin{array}{c}80 \\
(40-422)\end{array}$ \\
\hline & $>70$ & $\begin{array}{c}93 \\
(21 \%)\end{array}$ & $74.72 \pm 2.94$ & $\begin{array}{c}9.05 \\
(2.75-28.63)\end{array}$ & $\begin{array}{c}2.21 \\
(0.50-1.25)\end{array}$ & $\begin{array}{c}0.26 \\
(0.07-0.55)\end{array}$ & $\begin{array}{c}83 \\
(40-297)\end{array}$ \\
\hline Pathology re & $\begin{array}{c}\text { Chronic } \\
\text { prostatitis group }\end{array}$ & $\begin{array}{c}114 \\
(26 \%)\end{array}$ & $65.69 \pm 6.19$ & $\begin{array}{c}6.37 \\
(2.9-24.09)\end{array}$ & $\begin{array}{c}1.71 \\
(0.48-9.56)\end{array}$ & $\begin{array}{c}0.252 \\
(0.09-0.69)\end{array}$ & $\begin{array}{c}81 \\
(40-297)\end{array}$ \\
\hline & Only BPH group & $\begin{array}{c}324 \\
(74 \%)\end{array}$ & $64.39 \pm 7.09$ & $\begin{array}{c}6.86 \\
(2.75-29.85)\end{array}$ & $\begin{array}{c}1.805 \\
(0.24-0.26)\end{array}$ & $\begin{array}{c}0.248 \\
(0.03-0.82)\end{array}$ & $\begin{array}{c}79.5 \\
(40-422)\end{array}$ \\
\hline tPSA levels & $<10 \mathrm{ng} / \mathrm{dl}$ & $\begin{array}{l}325 \\
(74 \%)\end{array}$ & $63.93 \pm 7.09$ & $\begin{array}{c}5.995 \\
(2.75-9.91)\end{array}$ & $\begin{array}{c}1.43 \\
(0.24-5.28)\end{array}$ & $\begin{array}{c}0.239 \\
(0.03-0.82)\end{array}$ & $\begin{array}{c}68.50 \\
(40-234)\end{array}$ \\
\hline & $>10 \mathrm{ng} / \mathrm{dl}$ & $\begin{array}{c}113 \\
(26 \%)\end{array}$ & $67.34 \pm 6.91$ & $\begin{array}{c}13.84 \\
(10.04-29.85)\end{array}$ & $\begin{array}{c}3.05 \\
(0.36-1.25)\end{array}$ & $\begin{array}{c}0.230 \\
(0.02-0.56)\end{array}$ & $\begin{array}{c}95.0 \\
(40-422)\end{array}$ \\
\hline Total cohort & & $\begin{array}{c}438 \\
(100 \%)\end{array}$ & $64.82 \pm 7.19$ & $\begin{array}{c}6.82 \\
(2.75-29.85)\end{array}$ & $\begin{array}{c}1.69 \\
(0.24-1.25)\end{array}$ & $\begin{array}{c}0.235 \\
(0.02-0.82)\end{array}$ & $\begin{array}{c}74 \\
(40-422)\end{array}$ \\
\hline
\end{tabular}


$(\mathrm{PSA}<10 \mathrm{ng} / \mathrm{dl} \mathrm{p}<0.001$ and $\mathrm{r}=0.494, \mathrm{PSA}>10 \mathrm{ng} / \mathrm{dl}$ $\mathrm{p}<0.001$ and $\mathrm{r}=0.512$ ) (Table 4$)$.

The cut-off level for free PSA was determined as 1.285 $\mathrm{ng} / \mathrm{dl}$ for the prediction of prostate volume $>40 \mathrm{cc}$ (Table

5). The cut-off levels are shown in Table 5 for the other

Table 2.

Correlations between prostate volume and age, total PSA, free PSA, free PSA/total PSA ratio.

\begin{tabular}{|lccccccc|}
\hline & \multicolumn{2}{c}{ Total cohort } & \multicolumn{2}{c|}{ Chronic prostatitis group } & \multicolumn{2}{c|}{ Only BPH group } \\
\hline & $\begin{array}{l}\text { Correlation } \\
\text { coefficient }\end{array}$ & $\mathbf{p}$ & $\begin{array}{l}\text { Correlation } \\
\text { coefficient }\end{array}$ & $\mathbf{p}$ & $\begin{array}{c}\text { Correlation } \\
\text { coefficient }\end{array}$ & $\mathbf{p}$ \\
\hline PV - Age & 0.210 & $<0.001$ & 0.279 & 0.011 & 0.223 & $<0.001$ \\
PV - tPSA & 0.338 & $<0.001$ & 0.379 & $<0.001$ & 0.385 & $<0.001$ \\
PV - fPSA & 0.548 & $<0.001$ & 0.592 & $<0.001$ & 0.520 & $<0.001$ \\
PV-fPSA/tPSA & 0.363 & $<0.001$ & 0.359 & $<0.001$ & 0.287 & $<0.001$ \\
\hline PV, prostate volume; tPSA, total prostate-Specific antigen; fPSA, free prostate-specific antigen. & \\
\hline
\end{tabular}

Table 3.

Multivariate analysis of factors effecting the PV.

\begin{tabular}{|c|c|c|c|c|c|c|c|c|}
\hline & & \multicolumn{2}{|c|}{$\begin{array}{c}\text { Unstandardized } \\
\text { coefficients }\end{array}$} & \multirow{2}{*}{$\begin{array}{c}\begin{array}{c}\text { Standardized } \\
\text { coefficients }\end{array} \\
\beta \\
\end{array}$} & \multicolumn{3}{|c|}{$95 \% \mathrm{Cl}$} & \multirow[t]{2}{*}{ p } \\
\hline & & $\beta$ & SE & & & Lower bound & Upper bound & \\
\hline \multirow[t]{4}{*}{ Total cohort } & Age & 0.450 & 0.265 & 0.075 & 1.696 & -0.71 & 0.972 & 0.091 \\
\hline & tPSA & 0.023 & 0.890 & 0.003 & 0.026 & -1.726 & 1.772 & 0.979 \\
\hline & fPSA & 11.640 & 3.178 & 0.427 & 3.663 & 5.394 & 17.886 & $<0.001$ \\
\hline & fPSA/tPSA ratio & 25.800 & 31.322 & 0.067 & 0.824 & -35.763 & 87.363 & 0.411 \\
\hline \multicolumn{9}{|c|}{ Chronic prostatitis group } \\
\hline & Age & 0.476 & 0.677 & 0.068 & 0.703 & -0.873 & 1.825 & 0.484 \\
\hline & tPSA & 7.312 & 2.706 & 0.671 & 2.702 & 1.924 & 12,699 & 0.008 \\
\hline & fPSA & -6.615 & 8.341 & -0.224 & -0.793 & -23.220 & 9.991 & 0.430 \\
\hline & fPSA/tPSA ratio & 169.948 & 68.279 & 0.456 & 2.489 & 34.015 & 305.880 & 0.015 \\
\hline \multirow[t]{4}{*}{ Only BPH grou } & Age & 0.494 & 0.385 & 0.076 & 1.283 & -0.265 & 1.252 & 0.201 \\
\hline & tPSA & -1.437 & 1.387 & -0.158 & -1.036 & -4.169 & 1.295 & 0.301 \\
\hline & $\mathrm{fPSA}$ & 17.079 & 4.879 & 0.615 & 3.500 & 7.465 & 26.692 & $<0.001$ \\
\hline & $\mathrm{fPSA} / \mathrm{tPSA}$ ratio & -27.425 & 46.072 & -0.067 & -0.595 & -118.201 & 63.351 & 0.552 \\
\hline
\end{tabular}

Table 4.

Correlations between free PSA and PV in different age groups and total PSA levels.

\begin{tabular}{|c|c|c|c|c|c|c|c|c|c|c|}
\hline & \multicolumn{5}{|c|}{ Age } & & \multicolumn{4}{|c|}{ tPSA levels } \\
\hline & $\begin{array}{c}<60 \text { years } \\
n=121(28 \%)\end{array}$ & & $\begin{array}{c}60-70 \text { years } \\
n=224(51 \%)\end{array}$ & & $\begin{array}{c}>70 \text { years } \\
n=93(21 \%)\end{array}$ & & $\begin{array}{c}<10 \mathrm{ng} / \mathrm{dl} \\
n=325(74 \%)\end{array}$ & & $\begin{array}{c}>10 \mathrm{ng} / \mathrm{dl} \\
\mathrm{n}=113(26 \%)\end{array}$ & \\
\hline & $\begin{array}{l}\text { Correlation } \\
\text { coefficient }\end{array}$ & $p$ & $\begin{array}{l}\text { Correlation } \\
\text { coefficient }\end{array}$ & $p$ & $\begin{array}{l}\text { Correlation } \\
\text { coefficient }\end{array}$ & $p$ & $\begin{array}{l}\text { Correlation } \\
\text { coefficient }\end{array}$ & $p$ & $\begin{array}{l}\text { Correlation } \\
\text { coefficient }\end{array}$ & $p$ \\
\hline PV-fPSA & 0.546 & $<0.001$ & 0.506 & $<0.001$ & 0.487 & $<0.001$ & 0.494 & $<0.001$ & 0.473 & $<0.001$ \\
\hline
\end{tabular}

Table 5.

Receiver operating characteristic (ROC) curves for free PSA to predict whether prostate volume is $>40 \mathrm{cc}$ or $<40 \mathrm{cc}$.

\begin{tabular}{|lccccccc|}
\hline & AUC & SE & $\mathbf{p}$ & $\mathbf{9 5 \%} \mathbf{C l}$ & Sensitivity $(\%)$ & Specificity $(\%)$ & Cutoff levelT \\
\hline Total cohort & 0.780 & 0.036 & $<0.001$ & $0.709-0.851$ & 72.8 & 73.5 & 1.285 \\
\hline Only BPH group & 0.749 & 0.054 & $<0.001$ & $0.643-0.855$ & 66.5 & 76.0 & 1.495 \\
\hline Age $<60$ years & 0.782 & 0.059 & $<0.001$ & $0.667-0.897$ & 77.0 & 71.4 & 0.875 \\
\hline Age $60-70$ years & 0.738 & 0.067 & 0.001 & $0.606-0.869$ & 71.8 & 72.2 & 1.365 \\
\hline Age $>70$ years & 0.854 & 0.074 & $<0.001$ & $0.708-0.999$ & 90.4 & 80.0 & 1.325 \\
\hline PSA $<10 \mathrm{ng} / \mathrm{dl}$ & 0.753 & 0.044 & $<0.001$ & $0.666-0.840$ & 75.5 & 71.8 & 1.105 \\
\hline PSA $>10 \mathrm{ng} / \mathrm{dl}$ & 0.892 & 0.054 & $<0.001$ & $0.787-0.998$ & 89.3 & 80.0 & 1.660 \\
\hline AVAUC: Area under curve; SE: Standart error; Cl: Confidence interval. & & & & \\
\hline
\end{tabular}

subgroups in which free PSA was significant in predicting PV. The receiver operating characteristic (ROC) curves of each group for fPSA in the prediction of prostate volume $<40 \mathrm{cc}$ or $>40 \mathrm{cc}$ are shown in Figure 1.

\section{Discussion}

In the management of benign prostatic hyperplasia (BPH), urology guidelines recommend medical or surgical treatents according to different prostate volumes (PV). , accurate determination of PV is crucial for the choice of treatment and for the prediction of treatment outcomes such as the probability of urinary retention and the need for surgery (10-13). Nevertheless, BPH is a progressive disease and that progression is related to prostatic enlargement (14-16).

Transrectal ultrasound (TRUS) is more accurate in determining PV than transabdominal ultrasound so it is the reference method used to measure PV $(6,7)$. However, it is an expensive, time-consuming and uncomfortable method, and the equipment is not available in most primary settings. Moreover, in the initial evaluation of $\mathrm{BPH}$ patients, neither TRUS nor transabdominal ultrasound is recommended according to the urology guidelines. Digitalrectal examination (DRE) is simple to perform and useful for estimating the PV but it may assess small prostates as larger, and large ones as smaller. Therefore, there is a need for a reliable, practical and cheap method as an alternative to ultrasonography and DRE in daily practice (17).

Several independent investigators have verified the log-linear relationship between serum total PSA and PV in different populations and races with similar results (18). Hochberg et al. (19) and Coban et al. (20) found the correlation coefficient between total PSA and PV to be 0.39 and 0.41 , respectively. Similarly, in the present study, a significant correlation was determined between total PSA and PV $(r=0.33)$ but this result was not confirmed in the multivariate analysis (Table 3, p: 0.979). In agreement with the current study multivariate analysis findings, some investigators have proposed that the variability in the relationship between total PSA and PV can preclude the accurate prediction of the prostate volume using the total PSA alone for an individual patient $(9,21)$. 
Figure 1.

ROC curves of each group for free PSA to predict whether prostate volume is $>40$ or $<40$ cc.

The areas under curve and $p$ values of each group are shown in Table 5.
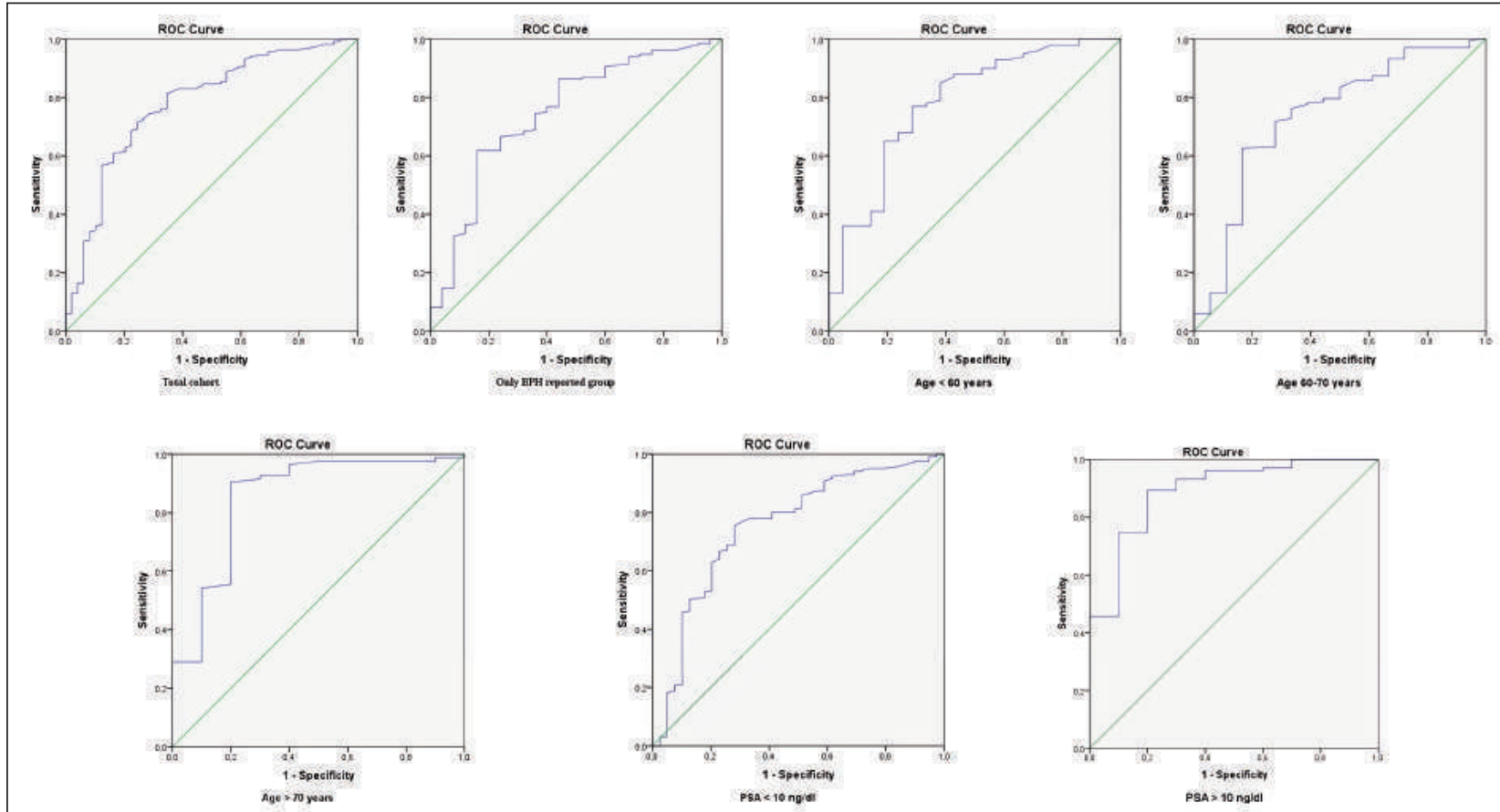

Although there have been numerous studies investigating the correlation of total PSA and PV in patients with $\mathrm{BPH}$, the relationship between free PSA and PV has received little attention. To the best of our knowledge, there have only been seven studies that have examining the relationship between free PSA and PV $(8,9,20,22-$ 25). All of these studies showed that free PSA was superior to total PSA for predicting PV, and this result was also demonstrated in the multivariate analyses in five of the aforementioned studies $(8,9,20,24,25)$. In the current study, both total PSA and free PSA were correlated with PV $(r=0.33, r=0.54$, respectively) but multivariate analysis showed a significant relationship only between free PSA and PV $(p<0.001)$. The superiority of the free PSA to total PSA found in the current study is consistent with findings in literature $(8,9,20,22-25)$. There were significant correlations between total PSA and PV in the multivariate analysis of 3 of the 5 previously mentioned studies $(8,20,24)$, whereas in the other two studies, a significant relationship was found only between free PSA and PV, as was the case in this current study $(9,25)$.

Prostatic inflammation appears to play a role in BPH pathogenesis and progression $(26,27)$ but in the aforementioned studies $(8,9,20,22,24,25)$, other than Mao et al. (23), who reported that patients with pathological results of only BPH were included in the study, there is no information about the presence of inflammatory conditions such as chronic prostatitis in the pathology results of patients. According to the pathology results of the current study, patients were divided into two groups as only BPH and BPH with chronic prostatitis. Significant correlations were found between free PSA and PV in both groups. However, in multivariate analysis, the BPH only group showed a significant correlation between free PSA and $\mathrm{PV}$, similar to the entire cohort, but that correlation was not found in $\mathrm{BPH}$ with chronic prostatitis group, whereas there was a significant correlation between total PSA and PV. It can be hypothesized that free PSA may be less influenced by prostatic inflammation in which serum total PSA elevation may occur as a result of disruption of the normal prostatic architecture, in other words, the greater increase in free PSA may result from a larger benign prostate tissue and prostatic inflammation contributes a greater increase to total PSA than free PSA. In the above-mentioned studies $(8,20,24)$ where a significant correlation was determined between total PSA and PV in multivariate analysis, this result could be attributed to possible prostatic inflammation. However, as prostatic inflammation is a pathological diagnosis, it may not be known before biopsy, especially in patients without symptoms associated with such a pathological condition. According to the current study results, the correlation between free PSA and prostate volume was comparatively decreased in the case of inflammation in the prostate. Therefore, the recommendations of previous studies and the current one for the use of free PSA to predict PV may be relatively limited in men with clinically unknown prostatic inflammation.

In this respect, the importance of defining this point, which has not been explored in previous studies, should be emphasized.

The relationship between free PSA and PV according to different age ranges and total PSA values was also examined in this study. The patients were stratified into three age groups of $<60$ years, $60-70$ years and $>70$ years. 
In all three age groups a significant correlation was determined between free PSA and PV and the highest degree of correlation was found in the group aged $<60$ years $(\mathrm{r}=0.54, \mathrm{r}=0.50, \mathrm{r}=0.48$ respectively). In three previous studies where patients were similarly classified according to age, a correlation between free PSA and PV was shown in all age groups (22-24). However, the age groups with the highest correlations were different from the current study. In two of the studies $(23,24)$ the highest correlations were seen in the group aged 60-70 years, while in the other study (22) it was the group of patients $>70$ years. In some studies $(20,22,23)$ patients with total PSA values $>10 \mathrm{ng} / \mathrm{dl}$ have been excluded to reduce the possibility of including patients with prostate cancer. Nevertheless, in some studies $(8,24)$ there is no information about the upper limit of total PSA while in another study (9), patients with total PSA > $10 \mathrm{ng} / \mathrm{dl}$ were included. In addition, no study has evaluated the correlation between free PSA and PV in patients with total PSA values $>10 \mathrm{ng} / \mathrm{dl}$. In the current study, the correlation was analysed between free PSA and PV in total PSA-stratified cohorts as total PSA above or below 10ng/dl. The data obtained showed that the value of the correlation coefficient was slightly greater for the total PSA $<10$ $\mathrm{ng} / \mathrm{dl}$ cohort than for the total PSA > $10 \mathrm{ng} / \mathrm{dl}$ cohort, suggesting that free PSA may correlate better to PV when the possibility of patients with prostate cancer decreases $(r=0.494, r=0.473$, respectively). However, from another perspective, because of the small difference in the correlation values between the groups, it can be said that in patients with total PSA > $10 \mathrm{ng} / \mathrm{dl}$, free PSA can be used safely for the prediction of PV.

In the current study, the diagnostic performance of free PSA as a proxy for PV was evaluated using ROC curves for each group, and free PSA was determined to be significant for PV with AUC values ranging from 0.73 to 0.89 for all subgroups (Table 5). In these analyses, the PV threshold was $40 \mathrm{cc}$, which is of great importance as guidelines have suggested not prescribing $5 \alpha$-reductase inhibitors to patients with a prostate volume $<40 \mathrm{cc}$ (4). In the ROC curves of the current study, when the cutoff value of free PSA was taken as $1.28 \mathrm{ng} / \mathrm{dl}$ to predict prostate volume $>40 \mathrm{cc}$, sensitivity and specificity were determined as $72.8 \%$ and $73.5 \%$, respectively and the AUC was 0.78 for the entire cohort. This result of AUC as 0.78 for free PSA to predict whether PV was $>40 \mathrm{cc}$ or $<40 \mathrm{cc}$ was slightly better than the values reported in previous studies (AUCs for references 8, 20, 22-24 were $0.72,0.75,0.71,0.75,0.75$, respectively).

There continues to be value in the use of free/total PSA for the stratification of the risk of prostate cancer and to decide on a biopsy for patients with $4-10 \mathrm{ng} / \mathrm{mL}$ total PSA and negative DRE. A previous study reported that prostate cancer was detected by biopsy in $56 \%$ of men with free/total PSA $<0.10$, but in only $8 \%$ with free/total PSA $>0.25 \mathrm{ng} / \mathrm{mL}$ (28). Those studies indicate that the probability of BPH increases as free PSA levels increase. Therefore, free PSA is more closely related to BPH and this link is parallel to the current study results. In the multivariate analysis results, the patients with chronic prostatitis pathology showed a significant relationship between free/total PSA and PV. This finding can be con- sidered to be related to inflammation-induced total PSA increase, as discussed above.

When the results were evaluated of the relationship between age and PV, a significant correlation $(r=0.21)$ was determined, similar to other studies in the literature $(8,9,20,22,23)$ but that correlation was not seen in the multivariate analysis (p: 0.091). This was consistent with the study of Morote et al. (9) whereas the opposite was reported in studies by Kayikci et al. (7) and Coban et al. (20) (p: $<0.01$ and $<0.01$, respectively).

The present study is one of a limited number of trials suggesting that free PSA is a strong predictor for PV and that it is better than total PSA. Initially, the efficacy of free PSA at predicting PV in patients with inflammatory pathology reports in addition to BPH and total PSA levels $>10 \mathrm{ng} / \mathrm{dl}$ were reported. These conditions were then evaluated as separate groups to eliminate any bias. In addition, separate cut-off levels for free PSA in the prediction of PV were established for different subgroups of patients. This study had some limitations, primarily the retrospective nature of the study, the probability of occult cancers that could not be detected by biopsy and the criteria used for subject recruitment on the basis of the indications for prostate biopsy rather than a clinical diagnosis of BPH. Nevertheless, the data suggest that because of the ability to obtain more accurate estimates of the PV without the help of more expensive, invasive diagnostic evaluations, free PSA could provide a more reasonable contribution in the proper management of patients with $\mathrm{BPH}$.

\section{Conclusions}

Although total PSA was significantly correlated with PV, this correlation was not shown in multivariate analyses unlike free PSA. The superiority of free PSA may be used to estimate PV with easily obtained serum tests and could be a useful tool for therapeutic decison-making and longitudinal follow-up in patients with $\mathrm{BPH}$. However, in patients with prostatic inflammation, considering that there is a significant relationship between free PSA and PV only in univariate analysis, it should be kept in mind that the efficacy of free PSA may be limited in this group of patients.

\section{REFERENCES}

1. Abrams P, Cardozo L, Fall M, et al. The standardisation of terminology of lower urinary tract function: report from the Standardisation Sub-committee of the International Continence Society. Neurourol Urodyn 2002; 21:167-178.

2. Kupelian V, Wei JT, O'Leary MP, et al. Prevalence of lower urinary tract symptoms and effect on quality of life in a racially and ethnically diverse random sample: the Boston Area Community Health (BACH) Survey. Arch Intern Med. 2006; 166:2381-2387.

3. Wilkinson AG, Wild SR. Is pre-operative imaging of the urinary tract worthwhile in the assessment of prostatism?. Br J Urol. 1992; 70:53-57.

4. Gravas S, Cornu JN, Drake MJ, et al. Guidelines on the Management of Non-neurogenic Male LUTS. Uroweb 2018. Available from:http://uroweb.org/guideline/treatment-of-non-neurogenic-male-luts/. 
5. Roehrborn CG. Accurate determination of prostate size via digital rectal examination and transrectal ultrasound. Urology. 1998; 51:19-22.

6. Terris MK, Stamey TA. Determinetion of prostate volume by transrectal ultrasound. J Urol. 1991; 145:984-987.

7. Trop-Pedersen S, Juul N, Jakobsen H. Transrectal prostatic ultrasonography: equipment, normal findings, benign hyperplasia and cancer. Scand J Urol Nephrol. Suppl 1988; 107:19-25.

8. Kayikci A, Cam K, Kacagan C, Tekin A, Ankarali H. Free prostate-specific antigen is a better tool than total prostate-specific antigen at predicting prostate volume in patients with lower urinary tract symptoms. Urology. 2012; 80:1088-1092.

9. Morote J, Encabo G, Lopez M, de Torres IM. Prediction of Prostate Volume Based on Total and Free Serum Prostate-Specific Antigen: Is It Reliable?. Eur Urol. 2000; 38:91-95.

10. Jacobsen SJ, Jacobsen DJ, Girman CJ, et al. Natural history of prostatism: risk factors for acute urinary retention. J Urol. 1997; 158:481-487.

11- Jacobsen SJ, Jacobsen DJ, Girman CJ, et al. Treatment for benign prostatic hyperplasia among community dwelling men: the Olmsted County study of urinary symptoms and health status. J Urol. 1999; 162:1301-1306.

12. Bosch JL, Bohnen AM, Groneveld FP. Validity of digital rectal examination and serum prostate specific antigen in the estimation of prostate volume in community-based men aged50 to 78 years: the Krimpen study. Eur Urol. 2004; 46:753-759.

13. Marberger MJ, Andersen JT, Nickel JC. Prostate volume and serum prostate-specific antigen as predictors of acute urinary retention: combined experience from three large multinational placebocontrolled trials. Eur Urol. 2000; 38:563-568.

14. Kaplan SA, Roehrborn CG, McConnell JD, et al. Long-term treatment with finasteride improves results in a clinically significant reduction in total prostate volume compared to placebo over the full range of baseline prostate sizes in man enrolled in the MTOPS trial. J Urol. 2008; 180:1030-2. Discussion 1032-1033.

15. Kaplan SA, Lee JY, Meehan AG, et al. Long-term treatment with finasteride improves clinical progression of benign prostatic hyperplasia in men with an enlarged versus a smaller prostate: data from the MTOPS trial. J Urol. 2011; 185:1369-1373.

16. Emberton M, Andriole GL, de la Rosette J et al. Benign prostatic hyperplasia: a progressive disease of aging men1. Urology 2003;61:267-273.
17. Roehrborn CG, Girman CJ, Rhodes T, et al. Correlation between prostate size estimated by digital rectal examination and measured by transrectal ultrasound. Urology. 1997; 49:548-557.

18. Trivedi MR, Choudhary BA. Digital rectal examination, transrectal ultrasound and prostate specific antigen as a triple assessment diagnostic tool for benign enlargement of prostate. Natl J Med Res. 2015; 5:244-248.

19. Hochberg DA, Armenakas NA, Fracchia JA. Relationship of prostate-specific antigen and prostate volume in patients withbiopsy proven benign prostatic hyperplasia. Prostate. 2000; 45:315-319.

20. Coban S, Doluoglu OG, Keles I, et al. Age and total and free prostate-specific antigen levels for predicting prostate volume in patients with benign prostatic hyperplasia. The Aging Male. 2016; 19:124-127.

21. Roehrborn CG, Boyle P, Gould AL, Waldstreicter J. Serum prostate-specific antigen as a predictor of prostate volume in men with benign prostatic hyperplasia. Urology. 1999; 53:581-589.

22. Choi H, Park JY, Shim JS, et al. Free prostate-specific antigen provides more precise data on benign prostate volume than total prostate-specific antigen in Korean population. Int Neurourol J. 2013; 17:73-77.

23. Mao Q, Zheng X, Jia X, et al. Relationships between total/free prostate-specific antigen and prostate volume in Chinese men with biopsy-proven benign prostatic hyperplasia. Int Urol Nephrol. 2009; 41:761-766.

24. Masuda H, Kawakami S, Sakura M, et al. Performance of free PSA better than total PSA for estimation of prostate volume in elderly men without prostate cancer (abstract). Eur Urol Suppl. 2011; 10:32.

25. Canto EI, Singh H, Shariat SF, et al. Serum BPSA outperforms both total PSA and free PSA as a predictor of prostatic enlargement in men without prostate cancer. Urology. 2004; 63:905-910.

26. Ficarra V, Rossanese $M$, Zazzara $M$, et al. The role of inflammation in lower urinary tract symptoms (LUTS) due to benign prostatic hyperplasia (BPH) and its potential impact on medical therapy. Curr Urol Rep. 2014; 15:463.

27. He Q, Wang Z, Liu G, et al. Metabolic syndrome, inflammation and lower urinary tract symptoms: possible translational links. Prostate Cancer and Prostatic Dis. 2016; 19:7.

28. Catalona WJ, Partin AW, Slawin KM, et al. Use of the percentage of free prostate-specific antigen to enhance differentiation of prostate cancer from benign prostatic disease: a prospective multicenter clinical trial. JAMA 1998; 279:1542-1547.

\section{Correspondence}

Sinan Avci, MD (Corresponding Author)

sinavci@yahoo.com

Efe Onen, MD

efe17@yahoo.com

Volkan Caglayan, MD

volkantuysuz@hotmail.com

Metin Kilic, MD

kilicmetin@hotmail.com

Murat Sambel, MD

muratsambel@hotmail.com

Sedat Oner, Associate Professor

sedatoner@yahoo.com

University of Health Sciences, Bursa Yuksek Ihtisas Training and Research

Hospital, Department of Urology, Bursa, Turkey 